\title{
The effect of thermal water aeration and water-rock interaction
}

\author{
Imre Czinkota ${ }^{1 *}$, János Szanyi², Balázs Kovács ${ }^{3}$, András Sebők \\ Ildikó Hajdok ${ }^{1}$, Márton Papp ${ }^{2}$
}

${ }^{1}$ Faculty of Agricultural and Environmental Science, Szent István University, Gödöllő, Hungary ${ }^{2}$ Department of Mineralogy, Geochemistry and Petrology, University of Szeged, Szeged, Hungary ${ }^{3}$ Department of Hydrogeology and Engineering Geology, University of Miskolc, Miskolc, Hungary

Received: January 28, 2015; accepted: February 21, 2016

This paper aims at determining the behavior of thermal water brought to surface and how this might impact reinjection wells and the rock during reinjection. The biggest problem is that reinjection wells are predisposed to choking. We searched for a method to examine this process, including a model for physico-chemical changes in the water-rock interaction. Two different samples of powdered rock (designated $\boldsymbol{\alpha}$ and $\boldsymbol{\beta}$ ) were analyzed using thermal water samples from production and reinjection wells. The $\mathrm{pH}$ shows significant differences between the samples from wells where free water treatment was carried out, and those from the aerated thermal waters, as well as for the rock sample. Basically, a decrease in sediment volume can be obtained by increasing the $\mathrm{pH}$. The salt effect was more coherent. Its result was an interesting case of W-shaped graphs from the producing well. On the other hand there is virtually no difference between the samples with acid titration.

Keywords: thermal water, aeration, $\mathrm{pH}$, water-rock interaction

\section{Introduction}

This research aims to determine the behavior of thermal water brought to the surface, and to determine its impact on reinjection wells and the rock during reinjection. In its course the main aim was to find a method to test this process and determine a model for physico-chemical changes at surface of the water and the water-rock

*Corresponding author: Imre Czinkota; Páter Károly u. 1, H-2100 Gödöllö, Hungary

E-mail: czinkota.imre@mkk.szie.hu 
interaction system. The water tests for $\mathrm{pH}$, salinity measurement and potentiometric titration were performed under airless as well as aerated conditions. The rock-water interaction studies were carried out using the well-known colloid-chemical sedimentary tests and models (Family and Vicsek 1991). Measurements and data collection were subjected to several repetitions. The results of these measurements went were statistically evaluated.

\section{The buffer capacity of thermal water - review}

Adhesion between particles (compared to other conditions) highly depends on the $\mathrm{pH}$ value of the water. The water, when exposed to contact with the components of air, will change its $\mathrm{pH}$. Two effects appear in the system at the same time. On the one hand the dissolved oxygen has an oxidation acidifying effect; on the other, high pressure forces a large amount of dissolved carbon dioxide to leave the system, resulting in an alkalinity effect on the environment. Which effect is greater depends on the particular water composition and the type of treatment. The composition of the water-soluble or departing materials is not directly linked to the concentration of hydrogen ions. The $\mathrm{pH}$ balance is a very complicated system which can change as a result. This is called the buffering capacity of the system. Some models to carry out this calculation exist, but due to the lack of many factors and components, they are highly inaccurate. Generally buffering capacity always has the smallest-impact dampening effect of $\mathrm{pH}$ changes on the balance in system transformation. The best-established way to measure a system's capacity is buffer potentiometric titration, when a quasi-steady state of a strong acid or alkali is added to the system (Szántó 1987).

The quasi-steady-state mode means that the relative speed of the reactions, taking place very slowly, always carried out the changes close to equilibrium rate, within the margin of error. This is easy to check: the $\mathrm{pH}$ meter had to recognize a constant value between the two. The chemical composition of the alkali or the acid was chosen to reduce any possible secondary reaction taking place in the system, in addition to the intended reaction of hydrogen and hydroxide ions. Usually hydrochloric acid and sodium hydroxide are used for this purpose, because the sodium and chloride ions are resistant to reaction with the components of the system.

\section{The effect of aeration on the $\mathrm{pH}$ of the water}

The water samples were stored in containers filled to the brim, transported to the laboratory and then stored until use. Some contents of the opened bottles were used and the remainder discarded. All measurements were performed as rapidly as possible, in new glass vessels. This procedure was designed to prevent contact by water samples with air, thus preventing gas exchange at the surface of the water. Aeration condition in our case means that air was continuously bubbled through the original water sample for two hours. Experiments were carried out with fresh air bubbled 
through the water samples, thus reducing the disturbing effect of long-term slow reactions due to storage. This procedure allows modeling the usage of geothermal water and allows the samples to be in contact with air, thereby resulting in the exchange of gases, which may occur during the treatment.

Sediment volume investigation

and literature review

Figures 1 and 2 below indicate increasing sediment volume in the case of increasing cohesion force between particles. Decreasing sediment volume will signify a reversal in cohesion force (Vold 1959; Luckham and Vincent 1983).

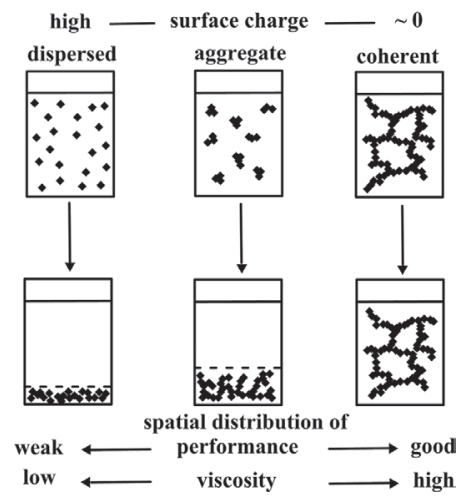

Fig. 1

The influence of the surface charge of the particles and the deposition of aqueous suspension aggregation (Patzkó 1998)

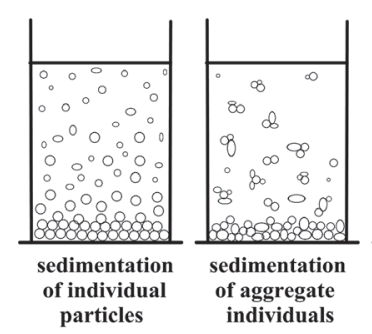

individual sedimentation

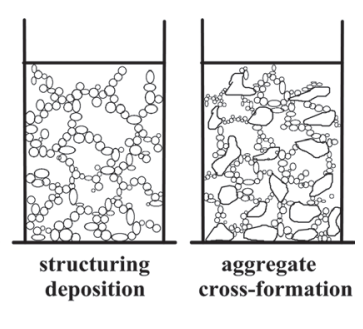

collective sedimentation

Fig. 2

Types of suspension sedimentation and deposition curves (Patzkó 1998)

Decreased attractive forces between particles means that they can be moved more easily by other forces. This means that the well can more easily become damaged by clogging caused by the repositioned moving particles (Sridharan et al. 1990; Ochi and Vernoux 1998).

\section{Materials and methods}

The rock samples were collected from near the reinjection boreholes, taking the depth of reinjection into account. The cores were milled and the resulting powders were analyzed with XRD and XRF spectroscopy. For the sediment analyses two different types of powdered rock were used. They are designated as $\boldsymbol{\alpha}$ and $\boldsymbol{\beta}$ rock samples. 
After XRF examination the powder samples were placed in the original sample containers and there measured for XRD tests. Macroscopically homogeneous samples were weighed out (0.2-0.2 grams for each sample) and manually pulverized in an agate mortar to achieve a $\sim 10$ micron diameter particle size. The prepared powders were placed in a standard glass (normal background sample holders).

Two water samples were used in the tests. The first samples came from the production well and the second samples from the buffer tank vessel of the reinjection well. All water samples were subjected to the two-water treatment:

a) Reductive treatment: The original water samples (filled to the brim of the vessel) were transported to the laboratory and stored until use. All measurements were performed in new glass vessels as rapidly as possible. Part of the content of the opened bottle was used and the remainder discarded. This procedure aimed at preventing contact of water samples with oxygen, thereby keeping the water samples in reductive condition.

b) Oxidative Water Treatment: Air was continuously bubbled through the original water samples for two hours. Experiments were carried out with fresh air bubbled through the water samples, thus reducing the disturbing effect of long-term slow reactions due to storage. This procedure was meant to model geothermal usage and allows oxygen in the air to be in contact with the water samples, thus keeping the water in an oxidation state.

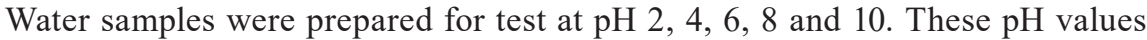
were used to carry out our sedimentation investigation. The measurement accuracy was $\pm 0.2 \mathrm{pH}$ by glass electrode. The salt-effect tests were carried out on $10 \mathrm{ml}$ of distilled water mixed with 1, 3, 5, 7 and $9 \mathrm{ml}$ of $5 \mathrm{~mol} / \mathrm{liter} \mathrm{KCl}$ solutions. Thereafter these solutions were pipetted to be measured. All treatments were performed in triplicate.

The sedimentation tests were carried out in $20 \mathrm{ml}$ test tubes, each tube being filled with $2 \mathrm{~g}$ of rock sample and $10 \mathrm{ml}$ of water sample. This was followed by two hours of shaking, and appropriate settling time. All of the test tubes in a rack were placed where the tubes and the camera were positioned in the same manner with respect to each other, to later compare results from the photos. The tubes were photographed under constant artificial lighting.

Based on the stored photos the relative height of the sediment was measured using InfranView software. Each repetition was measured relative to the rack. To determine the concentration of the buffer, $0.01 \mathrm{~mol} /$ liter of hydrochloric acid or sodium hydroxide solution was used for titration. The $\mathrm{pH}$ values were measured with Radelkis-made glass electrodes. The measured data were evaluated for statistical and graphical purpose using the ORIGIN 7.5 software. 


\section{Results}

\section{Results from the Powdered Rock}

The results of XRF and XRD studies are as follows:

As shown in Fig. 3, the element distribution in terms of the two rock samples is very similar. A significant difference in the Ca content is only shown in the $\boldsymbol{\beta}$ sample concentration, where twice as much is measured as in the $\boldsymbol{\alpha}$ sample.

Table 1 shows the qualitative and semi-quantitative pattern compositional data. The quality evaluation is based on the Rigaku PDXL 8.1 software package and ICDD (PDF2010) database. The quantitative evaluation was carried out with the half RIR (Reference Intensity Ratio) method. Accordingly, the semi-quantitative compositional data only represent a first approximation of what can be regarded as information.

Table 1

Comparative table of the semi-quantitative composition of rock samples

\begin{tabular}{lll}
\hline Sample & Main elements & Trace elements \\
\hline$\alpha$ & $\begin{array}{l}\mathrm{q}(\sim 50-60 \%), \text { ill } \pm \mathrm{mu}(\sim 15-20 \%), \\
\text { do }(\sim 10 \%)\end{array}$ & $\mathrm{ab}(\sim 5 \%), \mathrm{chl}(\mathrm{tr}), \mathrm{cc}(\operatorname{tr})$, hem $(\operatorname{tr}), \mathrm{rt}(\mathrm{ny})$, goe $(\operatorname{tr}) ?$ \\
\hline$\beta$ & $\begin{array}{l}\mathrm{q}(\sim 40-50 \%), \mathrm{ill} \pm \mathrm{mu}(\sim 20-25 \%), \\
\text { do }(\sim 10-15 \%)\end{array}$ & $\mathrm{ab}(\mathrm{tr}), \mathrm{chl}(\sim 5 \%), \mathrm{kaol}(\mathrm{tr}), \mathrm{cc}(\operatorname{tr})$, goe $(\operatorname{tr}) ?$ \\
\hline
\end{tabular}

q: quartz, ill \pm mu: illite \pm muscovite ( \pm illite-rich illite/szmectite), do: dolomite, ab: albite, chl: chlorite, cc: calcite, hem: hematite, rt: rutile, kaol: kaolinite, goe: goethite, tr: trace amount, ?: uncertain determination

In both samples, quartz, 10-Os phase (probably well-ordered 2M muscovite) and dolomite predominate. Additional components can be identified in very small amounts: albite, chlorite and calcite. The presence of traces of goethite cannot be determined clearly. Sample $\boldsymbol{\alpha}$ shows non-quantifiable amounts of hematite and rutile. It also appears that in sample $\boldsymbol{\alpha}$, a signal located at $7 \AA$ in double figures indicates the presence of kaolinite and chlorite; abnormal intensity ratios are likely.

\section{Effect of the $\mathrm{pH}$ on the sedimentation}

In the case of the $\boldsymbol{\alpha}$ samples, two sedimentation layers can be seen, very distinct from one another. This may be due to the mixture the two samples with significantly different surface properties, and to particle size of the rock. The individual layers were tested separately and also together. For $\boldsymbol{\beta}$ samples, only one sedimentation layer of rock can be seen. 


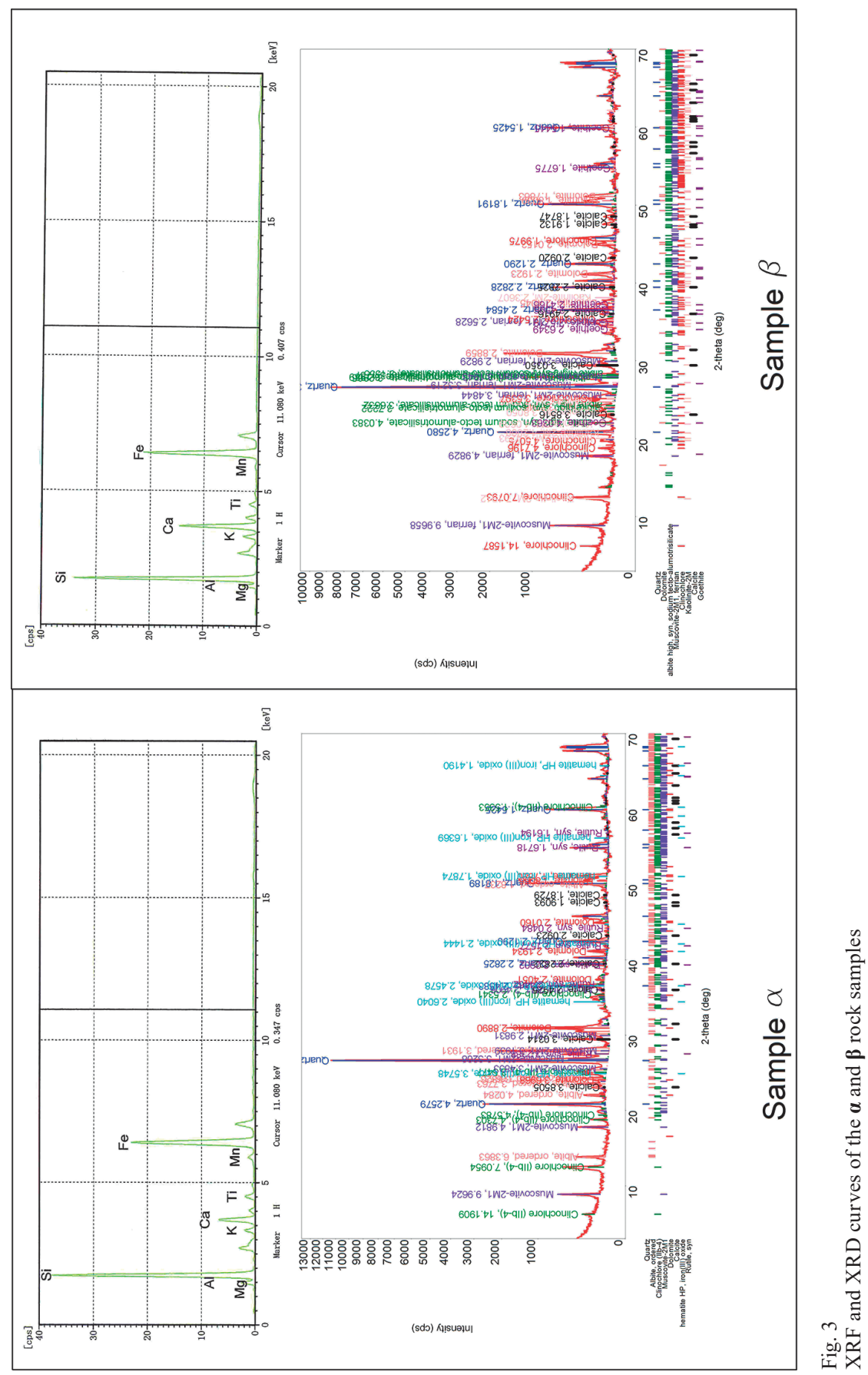




\section{Reductive tests}

The sediment volume of the $\boldsymbol{\beta}$ rock samples (which were taken from the reinjection wells) show a weak minimum of about $\mathrm{pH}$ 9. This means that the bonding force between the particles is the weakest at this $\mathrm{pH}$ value. Thus, they can be most easily removed at this $\mathrm{pH}$. In the case of water samples taken from the production well the sediment volume shows a fixed minimum about $\mathrm{pH}$ 8. This means that the bonding force between the particles is the weakest at this $\mathrm{pH}$ value. However, sediment volume peaked at $\mathrm{pH} 4$, suggesting that at this $\mathrm{pH}$ the production well's rock particles react to strongly stick together. Thereafter a further reduction in $\mathrm{pH}$ resulted in decreased attractive force between particles.

The $\boldsymbol{\alpha}$ rock samples, for each of the water samples, show a minimum in sediment volume at the same $\mathrm{pH}$ value of about 4.5. This means that the bonding force between the particles is the weakest at this $\mathrm{pH}$ value. Thus, they are the easiest to be moved at this $\mathrm{pH}$. Reducing or increasing the $\mathrm{pH}$ values results in an increase of the bonding forces between the particles. This is because at this value, certain types of particles are at the isoelectric point.

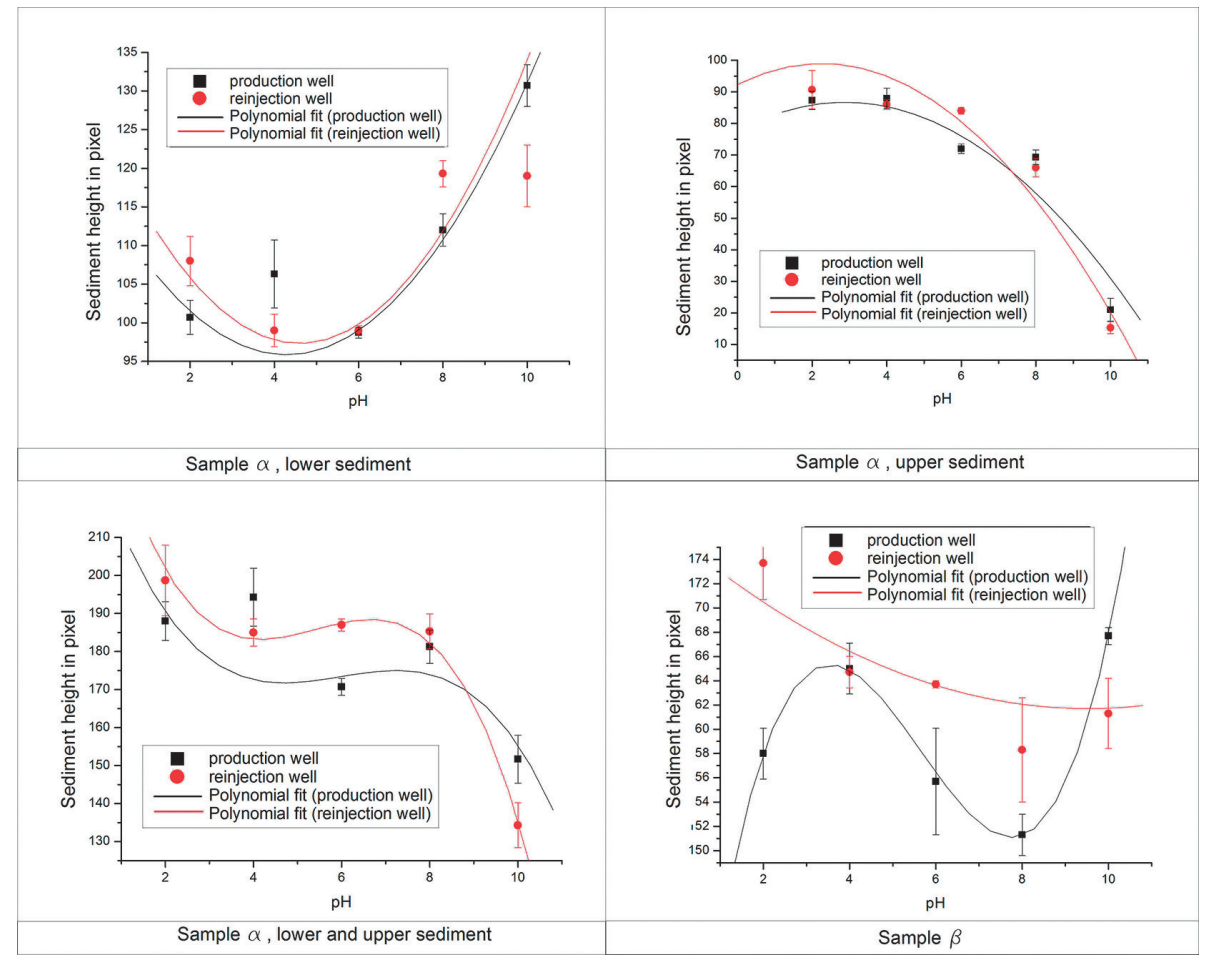

Fig. 4

Sediment volume curves in reductive water samples 
For each water sample, the volume of $\boldsymbol{\alpha}$ rock sample in the upper sediment produces a monotonous decrease at the same rate as when $\mathrm{pH}$ increases. The specific particles obviously have a highly negative charge. This can be because they are probably clay mineral particles. As a result of the hydrogen ions they lose their negative charge easily and they can clump together. Alkalizing can cause the repulsive force between the particles to greatly increase. In this case, the small particles can move very easily if the water is alkalizing.

For the $\boldsymbol{\alpha}$ rock sample, the amount of sediment volume in the two water samples changed by the same amount as the $\mathrm{pH}$ increased. The resultant of two different curves indicates that the sediment volume shows a minimum at $\mathrm{pH}$ value in the range of 4-5. This means a relatively weak adhesion. A maximum can be seen at $\mathrm{pH} 7$, which indicates a good adhesion between the particles. Further alkalizing of the system causes a drastic reduction, which indicates that the adhesion between the particles has become weaker. Sediment volume results of tests carried out under reductive conditions are illustrated in Fig. 4.

\section{Oxidative studies}

The sediment volume of water samples (which were taken from the reinjection wells) show a weak minimum of about $\mathrm{pH} 4$ (approximately). This means that the bonding force between the particles is the weakest at this $\mathrm{pH}$ value, and thus the particles most easily moved at this $\mathrm{pH}$. For both water samples the sediment volume shows a definite minimum at $\mathrm{pH} 9$ (approximately). This means that at this $\mathrm{pH}$ value occurs the weakest bonding force between the particles.

Figure 4 suggests that the maximum of sediment volume can be found at $\mathrm{pH} 4$ where the production well water's rock particles show strong adhesion. Further reduction in $\mathrm{pH}$ decreases the attractive effect between particles. In the case of the bottom sediment $\boldsymbol{\alpha}$ rock samples, the water samples of wells differ significantly from each other. In the case of the production wells, the sediment volume maximum shows almost the same $\mathrm{pH}$ value (about $4.5 \mathrm{pH}$ ). This suggests that the bonding force between the particles is the strongest at this $\mathrm{pH}$ value, and can only be separated with difficulty at this $\mathrm{pH}$. Reducing or increasing the $\mathrm{pH}$ values leads to an increase of the bonding forces between the particles. Studies with reinjection well water samples show that in this case, the bonding force only very slightly depends on the $\mathrm{pH}$. The increase in $\mathrm{pH}$ increases the sediment volume slightly, thus reducing the bonding force between the particles.

In the case of the two water samples from the upper sediment of the $\alpha$ rock sample, the sediment volume monotonously decreases when $\mathrm{pH}$ is increasing. The particular clay mineral particles have a strongly increasing negative charge when the $\mathrm{pH}$ is constant or increasing. This means that these particles bond easily because of the hydrogen ions which are causing the loss of the negative charge, while alkalizing the fluid increases the repulsive force between the particles. In this case the small particles may move easily while the water is being alkalized. 


\section{I. Czinkota et al.}

There is a significant difference between the water sampled at producing wells and that of the injection wells at the bottom of rock sediment. At the producing wells the sediment volume is almost the same and at $\mathrm{pH} 4.5$ it shows the maximum.

At this $\mathrm{pH}$ value occurs the strongest bonding force between the particles and it is most difficult to separate them. By reducing or increasing the $\mathrm{pH}$ value, the bonding force between the particles increases. The analyses of the reinjection well waters show that the bonding force depends slightly on the $\mathrm{pH}$. By increasing the $\mathrm{pH}$ value, the volume of sediment slightly increases as well, which means that the bonding force between the particles is decreasing. At the upper part of the sediment samples, the sediment volume is decreasing at almost the same rate as the $\mathrm{pH}$ increases.

With the rock sample, the sediment volume shows the maximum at around $\mathrm{pH} 5$, for all of the sediment in the case of producing wells, so there is a strong adhesive force between the particles at this $\mathrm{pH}$ value.

The particles have the weakest charge close to a value of $\mathrm{pH} 5$. They tend to be positive in a more acidic situation and negative in a more alkaline one; furthermore, they repel each other. The diagram shows a monotonous decreasing to around $\mathrm{pH} 6$ at

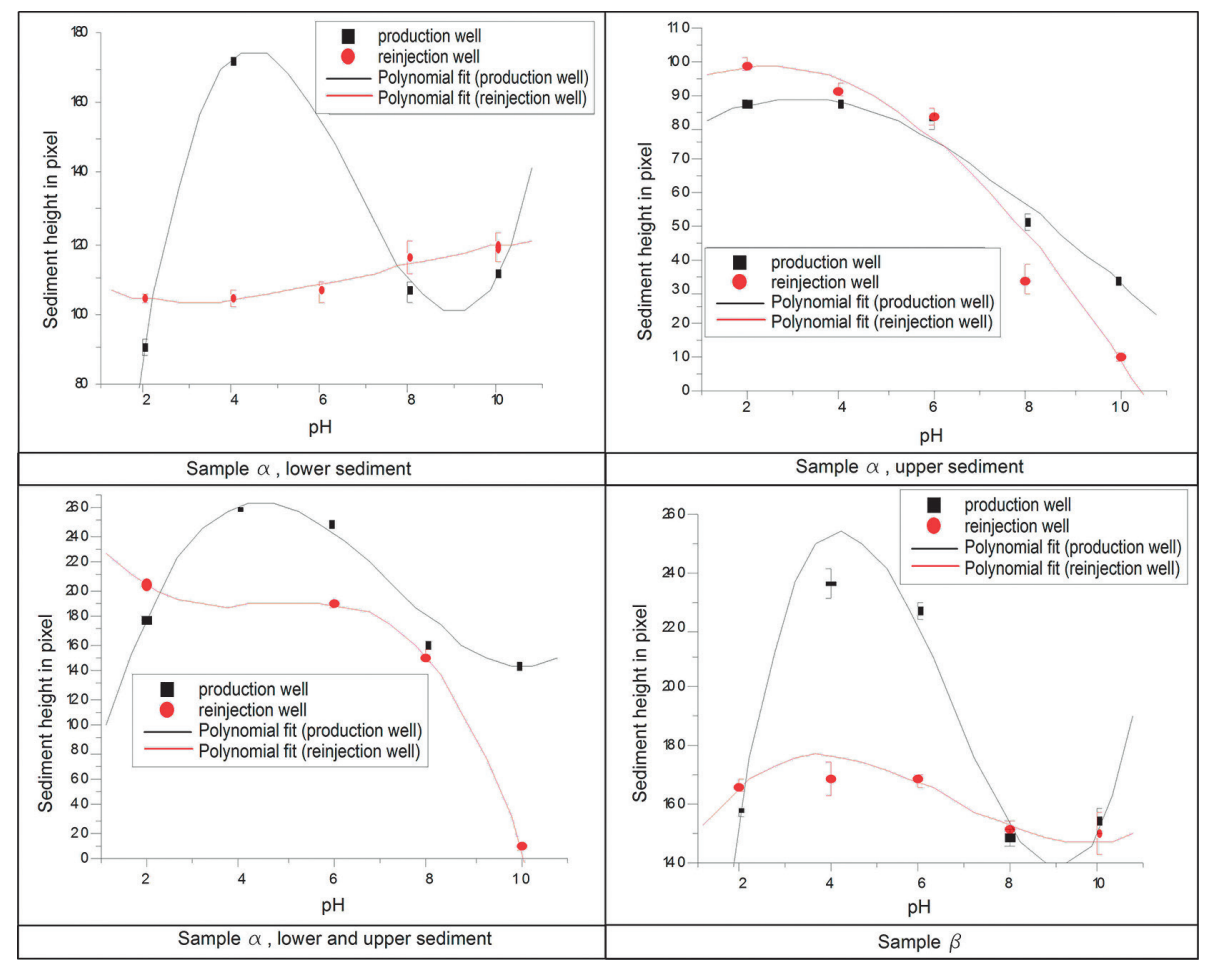

Fig. 5

Sediment volume diagrams with oxidative water samples 
the reinjection wells. This indicates good adhesion between the particles. By creating more alkaline conditions in the system we can dramatically experience the decrease in adhesion, which indicates that this force of the particles becomes weaker.

Figure 5 shows the results of the sediment volume in the oxidative conditions.

\section{Effect of aeration on the water $\mathrm{pH}$}

The $\mathrm{pH}$ measurement results are shown in Fig. 6. Every sample differs significantly from the others. The aerated sample means a bubbled one; the producing and stamping obviously indicates the origin of the water sample. Both wells show that the aerated sample's $\mathrm{pH}$ is significantly higher than that of the original water sample. This is due to the intense bubbling, which eliminated large quantities of carbon dioxide from the sample, thus decreasing the concentration of carbonic acid and hydrogen ions.

The reinjection wells' original $\mathrm{pH}$ is less, which is due to the contact with oxygen by the sample through oxidation at the surface; therefore, compared to the intense bubbling, a much smaller amount of carbon dioxide was removed from the system.

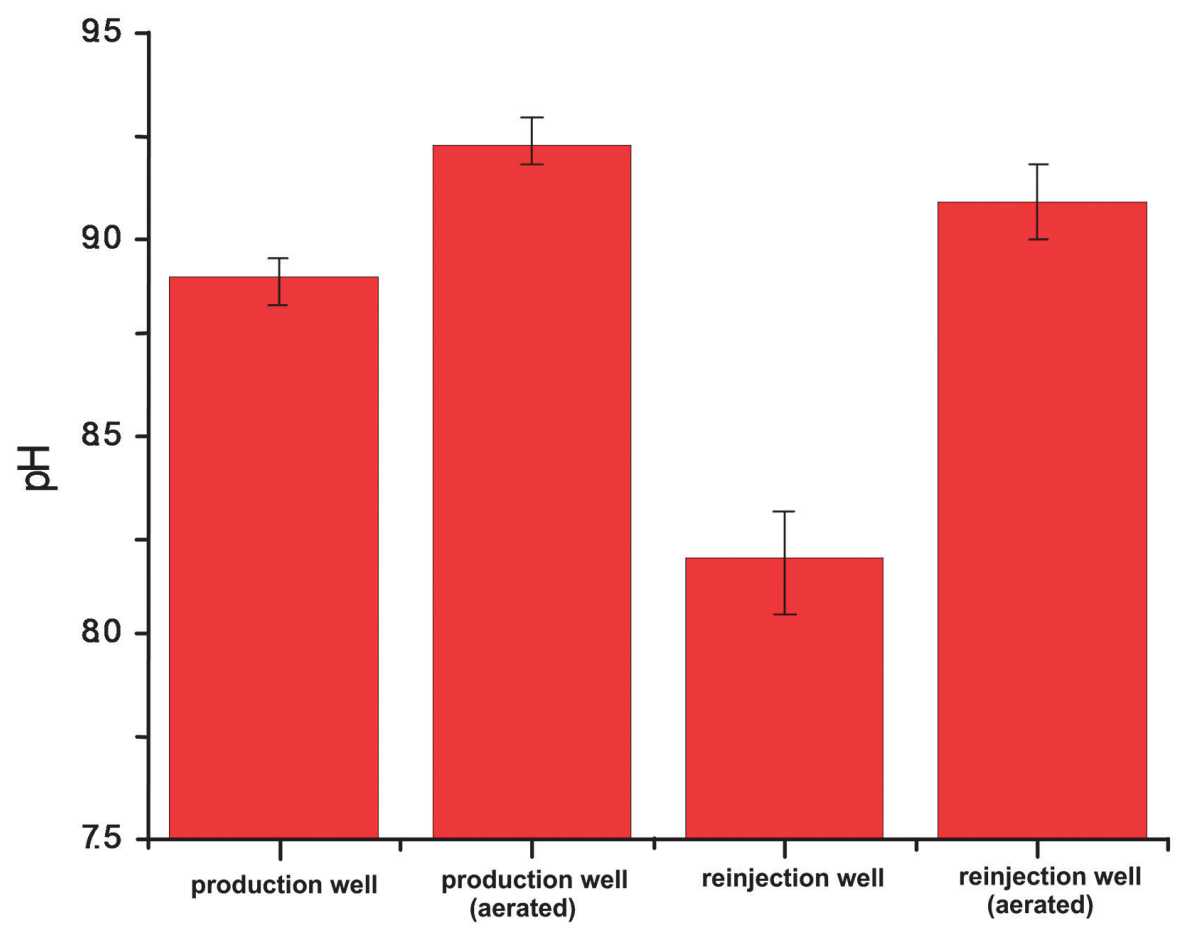

Fig. 6

The analyzed water sample changes in the $\mathrm{pH}$ due to aeration 
The acidifying effect of oxidation is more active, in addition to the much larger effect of $\mathrm{pH}$-changing carbonic acid.

The same is valid for the phenomenon observed with aerated samples, because there is a small but significant $\mathrm{pH}$ decrease as well.

The effect of the carbon dioxide removal through bubbling, which raises the $\mathrm{pH}$ as well, is roughly equivalent, so the difference is increased by oxygen.

\section{Titration graphs and analysis}

Below are the measured titration diagrams (Fig. 7). We indicated the $\mathrm{pH}$ value with black font and derived ones with red font. At a minimum we are looking for the inflection or breakthrough points, which are indicated by blue lines:

In the case of acid titration there is basically no difference between the samples (Table 2). From the measured inflection points we can say that in very small amounts, on the basis of the materials initially found at the corresponding $\mathrm{pH}(\sim 8)$, it corresponds to the carbonic acid equilibrium according to the following equation:

$$
\begin{aligned}
\mathrm{HCO}_{3(\mathrm{aq})}^{-}+\mathrm{H}_{2} \mathrm{O}_{(\mathrm{aq})} & \rightleftharpoons \mathrm{OH}_{(\mathrm{aq})}^{-}+\mathrm{H}_{2} \mathrm{CO}_{3(\mathrm{aq})} \\
K_{\mathrm{b}} & \approx 10^{-8}
\end{aligned}
$$

In other words, an already weak alkaline solution, by adding hydrogen ions, can remove hydroxide ions. That is why the original hydrocarbons form carbonic acid ions, and why we can say that surface water treatment did not change the concentration of hydrocarbon ions in the solution, as it is nearly the same in the producer and the reinjection wells, namely $0.7 \mathrm{mmol} / \mathrm{dm}^{3}$. The second inflection point is based on the $\mathrm{pH}$ carboxyl groups and identified by the following equation:<smiles>[R]C(=O)O[14CH2]OC([R])=O</smiles>

The $\mathrm{R}$ (radical) may indicate different organic groups. This means that the added hydrogen ions, in response to the carboxyl, react with ions to form carboxylic acids (Vetter and Kandarpa 1982). The conclusion can be drawn that the surface water treatment did not change the concentration of hydrocarbon ions in the solution, since both at production and reinjection wells it is nearly equal to the value of (approx.) $3.5 \mathrm{mmol} / \mathrm{dm}^{3}$. There was a slightly decrease in the solution of this component for the reinjection and aerated well. This may indicate some volatile acidic degradation of the material surface treatment, or some kind of basic, reducing acidity can fall apart in the water on the surface, which was observed after the removal of carbon dioxide. The initial titration graph shows minor quantitative differences. However, it also shows that these differences are not really significant; the specific method of 
The effect of thermal water aeration and water-rock interaction 317

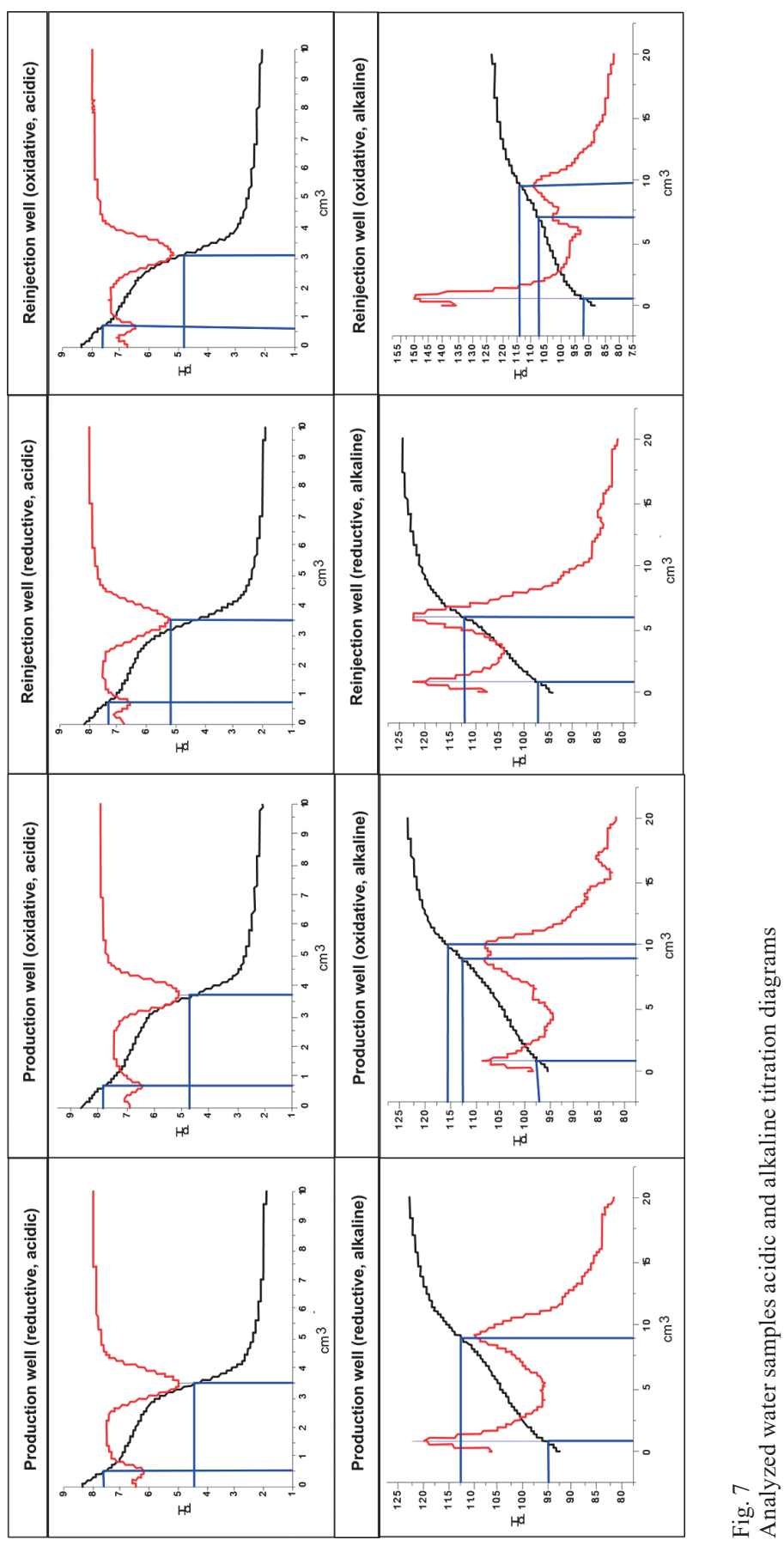

Central European Geology 58, 2015 
Table 2

Inflection points of the titration graphs

\begin{tabular}{|c|c|c|c|c|c|c|}
\hline Sample & $\begin{array}{l}\text { Volume } \\
\left(\mathrm{cm}^{3}\right)\end{array}$ & $\begin{array}{l}\text { Concentration } \\
\left(\mathrm{mmol} / \mathrm{dm}^{3}\right)\end{array}$ & pH & $\begin{array}{l}\text { Volume } \\
\left(\mathrm{cm}^{3}\right)\end{array}$ & $\begin{array}{l}\text { Concentration } \\
\left(\mathbf{m m o l} / \mathbf{d m}^{3}\right)\end{array}$ & pH \\
\hline $\begin{array}{l}\text { Production well } \\
\text { (reductive, acidic) }\end{array}$ & 0.47 & 0.47 & 7.63 & 3.47 & 3.47 & 4.37 \\
\hline $\begin{array}{l}\text { Production well } \\
\text { (oxidative, acidic) }\end{array}$ & 0.67 & 0.67 & 7.83 & 3.67 & 3.67 & 4.66 \\
\hline $\begin{array}{l}\text { Reinjection well } \\
\text { (reductive, acidic) }\end{array}$ & 0.67 & 0.67 & 7.37 & 3.51 & 3.51 & 4.28 \\
\hline $\begin{array}{l}\text { Reinjection well } \\
\text { (oxidative, acidic) }\end{array}$ & 0.67 & 0.67 & 7.6 & 3.07 & 3.07 & 4.84 \\
\hline $\begin{array}{l}\text { Production well } \\
\text { (reductive, alkaline) }\end{array}$ & 0.7 & 0.7 & 9.49 & 8.98 & 8.98 & 11.24 \\
\hline $\begin{array}{l}\text { Production well } \\
\text { (oxidative, acidic) }\end{array}$ & 0.83 & 0.83 & 9.73 & 8.85 & 8.85 & 11.25 \\
\hline $\begin{array}{l}\text { Reinjection well } \\
\text { (reductive, alkaline) }\end{array}$ & 0.9 & 0.9 & 9.75 & 6.01 & 6.01 & 11.23 \\
\hline $\begin{array}{l}\text { Reinjection well } \\
\text { (oxidative, alkaline) }\end{array}$ & 0.67 & 0.67 & 9.28 & 9.58 & 9.58 & 11.37 \\
\hline
\end{tabular}

measuring is accurate enough to show it. The alkaline titration analysis shows that the first inflection point is at around $\mathrm{pH} 9-9.5$. We cannot explain the organic and carbonic acid balance. These include, for example, aluminum or iron complexes, and small or medium molecular weight organic ligands.

The second inflection point is easy to identify: the value of the $\mathrm{pH}$ is at around 11:

$$
\begin{gathered}
\mathrm{HCO}_{3 \text { (aq) }}^{-}+\mathrm{H}_{2} \mathrm{O}_{(\mathrm{aq})} \rightleftharpoons \mathrm{H}_{3} \mathrm{O}_{(\mathrm{aq})}^{+}+\mathrm{CO}_{3 \text { (aq) }}^{2-} \\
K_{\mathrm{a} 2} \approx 10^{-11}
\end{gathered}
$$

Thus, in this case, carbonate ions in the water are transformed, in response to the hydrogen ions, into hydrocarbons. Here we find significant differences between the water samples. As it can be seen, the effect of aeration causes the appearance of a new compound, which can provide protons while on the surface. This compound could 
convert during the bubbling process. This can be a transformation of an organic material, or it can also be formed by oxidation of inorganic compounds (e.g. a complex $\mathrm{Fe}^{3+}$ ). It is worth comparing the results of the production and injection wells. On the titration graphs it is very difficult to observe the component which generates and influences the buffering capacity of water, but it is obvious that chemical reactions are taking place in the system.

\section{Discussion}

In our studies two different samples of powdered rock (designated as $\boldsymbol{\alpha}$ and $\boldsymbol{\beta}$ ) were used, which were analyzed with thermal water samples from production and reinjection wells. In the case of the water samples original (not in contact with atmospheric oxygen) and treated (subjected to two hours blowing through of atmospheric air) forms were utilized. Water samples for $\mathrm{pH}$ tests $2,4,6,8$ and 10 were adjusted to $\mathrm{pH}$ values for sedimentation investigations. For the salt impact tests $10 \mathrm{ml}$ of the samples were mixed with 1, 3, 5, 7 and $9 \mathrm{ml}$ of $5 \mathrm{~mol} / \mathrm{L} \mathrm{KCl}$ solution, and then from these the proper solution for measuring was extracted. All treatments were carried out three times. Finally, we also analyzed pictures of the sediment.

The results are summarized as follows:

In one rock sample we observed two different speeds of sedimentary solid phase, of larger and of a much smaller particle size. According to the XRD and XRF results on the rock samples, we can conclude that both samples of quartz, $10 \AA$ phase (probably well-ordered $2 \mathrm{M}$ muscovite) and dolomite predominate. Additional components are albitic feldspar, chlorite, calcite which can safely be identified; the presence of goethite cannot be ruled out. In the $\boldsymbol{\alpha}$ sample there is hematite and rutile as well. For the $7 \AA$ reflection signal in double figures in the $\boldsymbol{\alpha}$ samples, the presence of kaolinite and chlorite as abnormal intensity ratios are suggested. These different results are from the powdered rock labeled $\boldsymbol{\alpha}$, which is in two phases.

The $\mathrm{pH}$ shows significant differences between the samples from wells free of water treatment and those from the thermal aerated waters, and for the rock sample as well. Basically we can obtain decreasing sediment volumes by increasing the $\mathrm{pH}$, which reduces the cohesive forces between the particles. In many cases, we found extreme values in the tested range. This means that there is a maximum and minimum cohesive particle that produces a $\mathrm{pH}$ range. In general more multi-function $\mathrm{pH}$ testing should be conducted on the rock samples. The details of the treatments were given and evaluated.

From the point of view of the salt effect the picture is more coherent. We obtained an interesting case of the $\mathrm{W}$ shaped graphs from the producing wells (which are very well modeled by a fourth-order function). This changes frequently at the reinjection well. Based on these results, the tested system has two isoelectric points. The exact explanation of this would require further study.

Both wells show that the aerated sample $\mathrm{pH}$ is significantly higher than that of the original water sample. This is due to intense bubbling, resulting in the removal 
of large quantities of carbon dioxide from the system, causing the carbon dioxide, and thus the hydrogen concentration, to decrease. The reinjection wells' initial pH is lower, which is due to contact made along the way in pipes of oxidized surfaces on the sample. Thus, compared to samples subjected to intensive bubbling, a much smaller amount of carbon dioxide is removed from the system. This effect can avoid oxidation acidifying, in addition to a much larger change in $\mathrm{pH}$ causing a carbonic acid effect.

The titration diagrams allow the following conclusions:

There is virtually no difference between the samples with acid titration. From the measured points of inflections it would seem that the material is initially found in very small quantities, corresponding to the carbonic acid equilibrium. The alkaline titration analysis shows that the first inflection point comes from the appearance of inorganic compounds. Among the inorganic compounds there are also a few which are capable of producing protons. These include complexes of aluminum or iron, and low or medium molecular-weight organic ligands. The second inflection point shows the evolution of carbonate ions into hydrocarbons. We find a significant difference between the production and injection wells' water samples in the alkaline titration.

\section{References}

Family, F., T. Vicsek (Eds) 1991: Dynamics of Fractal Surfaces. - World Scientific, Singapore, New Jersey, $492 \mathrm{p}$.

Luckham, P.F., B. Vincent 1983: The controlled flocculation of particulate dispersions using small particles of opposite charge. IV. Effect of surface coverage of adsorbed polymer on heteroflocculation. - Colloids and Surfaces, 6/2, pp. 119-133.

Ochi, J., J. Vernoux 1998: Permeability decrease in sandstone reservoirs by fluid injection, hydrodynamic and chemical effects. - Journal of Hydrology, 208, pp. 237-248.

Patzkó, Á. 1998: A kolloidika alapjai (The fundaments of colloid science). - Szegedi Egyetemi Kiadó, Szeged, 130 p. (in Hungarian)

Sridharan, A., S.M. Rao, S. Joshi 1990: Classification of expansive soils by sediment volume method. Geotechnical Testing Journal, 13/4, pp. 375-380.

Szántó, F. 1987: A kolloidkémia alapjai (The fundaments of colloid chemistry). - Gondolat Kiadó, Budapest, 336 p. (in Hungarian)

Vetter, O.J., V. Kandarpa 1982: Reinjection and injection of fluids in geothermal operations (state of the art). - DOE/DGE Report, US Department of Energy, Washington, DC, 104 p.

Vold, M.J. 1959: Sediment volume and structure in dispersions of anisometric particles. - Journ. Phys. Chem., 63/10, pp. 1608-1612. 